\title{
Is It Idiopathic Pulmonary Fibrosis or Not?
}

\author{
Mary Salvatore, MD, Genta Ishikawa, MD, and Maria Padilla, MD
}

Pulmonary fibrosis is not uncommon. Usual interstitial pneumonitis (UIP)/idiopathic pulmonary fibrosis (IPF) is the most common of the idiopathic pulmonary fibrotic diseases and has the worst prognosis with a mean life expectancy of $\mathbf{3 . 8}$ years. The American Thoracic Society has provided guidelines for the accurate diagnosis of IPF.

In 2014, 2 antifibrotic medications were approved in the United States that target the multiple fibrotic pathways of UIP, which increased the need for early and accurate diagnosis of IPF. The early and correct diagnosis is hampered by mimickers that include nonspecific interstitial pneumonitis, chronic hypersensitivity pneumonitis, and fibrotic sarcoidosis. Careful history taking, serologic testing, and Computer Tomography (CT) inspection can frequently make the correct diagnosis without need of invasive procedure. The purpose of this article is to share the most important aspects of the clinical and radiology presentation of IPF and its mimickers to enhance primary care clinician's ability to correctly and noninvasively diagnose UIP/IPF. (J Am Board Fam Med 2018;31:151-162.)

Keywords: Idiopathic Pulmonary Fibrosis, Primary Health Care, Sarcoidosis

Fibrosis is the final common pathway of many injuries to the lung. Perhaps the earliest known cause of fibrosis was inhaled antigen-mediated hypersensitivity pneumonitis. In 1713, Bernadino Ramazzini recorded the health hazards associated with 52 occupations. He detailed the breathing difficulties related to maple-bark mold causing hypersensitivity pneumonitis. ${ }^{1}$ In the early 1900 s asbestos was touted as a fire-retardant material with excellent insulating capability. By the 1970s it was known to cause lung fibrosis and its usage was banned by the US Environmental Protection Agency. Radiation Fibrosis occurs in the lung when it is exposed to greater than $20 \mathrm{~Gy}$ of radiation. ${ }^{2}$ Osteophytes of the spine can cause pulmonary fibrosis from mechanical irritation. ${ }^{3}$

This article was externally peer reviewed.

Submitted 7 July 2017; revised 22 September 2017; accepted 26 September 2017.

From the Department of Radiology, Icahn School of Medicine at Mount Sinai, New York, NY (MS); Department of Pulmonary Medicine, Icahn School of Medicine at Mount Sinai, New York (GI, MP).

Funding: none.

Conflict of interest: Dr. Salvatore is a lecturer at Genentech, Boehringer Ingelheim, and Rockpointe.

Corresponding author: Mary Salvatore, MD, Department of Radiology, Mount Sinai School of Medicine, 1 Gustave Levy Place, New York, NY 10029 (E-mail: mary.salvatore@mountsinai.org).
In 1969 Liebow and Carrington ${ }^{4}$ described a group of idiopathic interstitial pneumonias that included usual interstitial pneumonia (UIP) which is associated with the clinical diagnosis of idiopathic pulmonary fibrosis. The criteria for diagnosing UIP have been well established. Recently, the American Thoracic Society/European Respiratory Society provided an update of the Classification of Idiopathic Interstitial Pneumonias (IIPs). Four categories were defined: chronic-fibrosing IIPs, acute or subacute IIPs, smoking-related IIPs, and rare IIPs. ${ }^{5}$ In clinical practice the fibrosing IIPs, which include usual interstitial pneumonitis (UIP) and fibrotic nonspecific interstitial pneumonitis (NSIP), are most frequently encountered and provide the greatest diagnostic dilemma because of their overlapping clinical, radiologic, and pathologic presentation. Chronic hypersensitivity pneumonitis (CHP) and fibrotic sarcoidosis (S4), which are not listed as idiopathic fibrosis, further complicate diagnosis because of their relative frequency and similar presenting features. The goal of this review article is to provide an overview of the clinical and radiologic diagnosis of UIP/idiopathic pulmonary fibrosis (IPF) and mimickers of the disease with the main goal being ability to answer the question, "Is it IPF or not?" Differentiation of fibrosis is important because treatments are differ- 
ent as well as prognosis. IPF is treated with antifibrotic medications, NSIP and S4 are often treated with anti-inflammatory medications, and CHP requires removal of the antigen causing disease. Early disease diagnosis leads to improved outcomes for patients.

\section{UIP/IPF}

\section{Clinical}

UIP/IPF is classified as a fibrosing IIP and is the most common subtype of IIPs. UIP is the radiographic pattern and IPF is the clinical diagnosis associated with a UIP pattern. It is limited to the lungs and has the worst prognosis with median survival estimate of 3.8 years. ${ }^{6-8}$ It is defined as a chronic fibrosing interstitial pneumonia of unknown cause with a UIP pattern on surgical lung biopsy or on high-resolution Computer Tomography (CT) scan (histologic UIP pattern: variegated pattern of alternating areas of normal or nearnormal lung, juxtaposed to areas of lung remodeling with temporal heterogeneity of fibrosis consisting of scattered fibroblastic foci in the background of dense acellular collagen, and honeycombing). ${ }^{9}$ It frequently occurs in the elderly male population (median age, 66 years). Risk factors for disease include cigarette smoking and gastroesophageal disease. ${ }^{8}$ Most patients with IPF demonstrate a gradual worsening of lung function over years, whereas some patients experience episodes of acute respiratory worsening despite previous stability (ie, acute exacerbation). ${ }^{8}$ On physical examination the patients have crackles at the posterior lung bases. Pulmonary function tests demonstrate restrictive physiology with diminished Diffusion Capacity of Lungs for Carbon Monoxide (DLCO) and Forced Vital Capacity (FVC). According to the ATS/ERS/ JRS/ALAT 2011 revised diagnostic criteria, the IPF diagnosis is securely established based on highresolution computed tomography (HRCT) findings of UIP, and/or pathologic criteria, in the absence of known cause of lung fibrosis such as collagen vascular disease, drug toxicity, sarcoidosis, and various environmental exposures (i.e., CHP). ${ }^{8}$ In some patients with definitive HRCT findings (ie, UIP pattern; discussed in the following "Radiology" section), surgical lung biopsy can be avoided in the diagnosis of IPF. The multidisciplinary discussion among pulmonologists, radiologists, and pathologists experienced in the diagnosis of interstitial lung disease
(ILD) increases the accuracy of the diagnosis. Most ILD centers in the United States have a dedicated ILD multidisciplinary conference, as vital part of the diagnosis and referring patients to those centers would expedite the diagnosis. ${ }^{10}$

Until recently, it had been believed that UIP/ IPF was driven by uncontrolled inflammation, therefore many anti-inflammatory medications (prednisone, azathioprine, $\mathrm{N}$-acetylcysteine, interferon- $\gamma$, etc.) were previously administered or tested in patients with UIP/IPF. ${ }^{11,12}$ However, recent evidence has demonstrated inefficacy or harm from these and they are not recommended therapy in the treatment of IPF. ${ }^{8}$ In the past decade, therapeutic modalities have been targeted at mechanisms involved in the wound healing cascade (ie, antifibrotic mechanism). In late 2014, 2 drugs, pirfenidone and nintedanib, were approved by the Food and Drug Administration (FDA) for treatment of IPF based on their ability to slow disease progression. Pirfenidone, an antifibrotic drug that reduces lung fibrosis through down-regulation of the production of growth factors and procollagens I and II, was shown to reduce the rate of FVC decline as well as a statistically significant improvement in progression-free survival in the Assessment of Pirfenidone to Confirm Efficacy and Safety in Idiopathic Pulmonary Fibrosis (ASCEND) trial ${ }^{11}$, which followed the PIPF004 and PIPF006 trials. ${ }^{13}$ Likewise, nintedanib, a tyrosine kinase inhibitor, originally developed as an antivascular agent for oncology indications, was tested for efficacy against IPF in several trials ${ }^{14,15}$, and these showed a significant impact in rate of FVC decline relative to placebo. These trials were not powered to answer effect on survival and given the lack of the data of long-term efficacy of these agents; UIP/IPF remains a refractory disease with guarded prognosis for which further investigation of new innovative therapies is necessary.

\section{Radiology}

Radiology plays an important role in the early and correct diagnosis of UIP. HRCT scans of the chest should be performed in the supine position in full inspiration. Intravenous contrast is not indicated. Slice thickness should be between 1 and $1.25 \mathrm{~mm}$. Prone CT images can be acquired if the patient has early disease and there is a concern that the findings may represent dependent atelectasis. Expiratory images can be obtained on initial imaging if hyper- 
sensitivity pneumonitis is in the differential diagnosis because expiratory imaging demonstrates air trapping, one of the radiographic hallmarks of hypersensitivity pneumonitis.

In 2011, the ATS/ERS/JRS/ALAT published evidence based guidelines for the diagnosis of IPF. ${ }^{8}$ A "UIP pattern" radiographically was defined as subpleural basilar predominant fibrosis, reticulations, honeycombing, and absence of features that would support an alternate diagnosis (Figure 1). The correct diagnosis of honeycombing is important and as such it deserves extra attention. The definition of honeycombing described by Webb et $\mathrm{al}^{16}$ is "rounded lucencies with shared walls in vertical stacks that are subpleural and occur in association with other findings of fibrosis." The interreader agreement for honeycombing (HC) is low ranging, from 0.21 to 0.31 in previous reports ${ }^{17}$ due to mimickers of honeycombing, which include bronchiolectasis, paraseptal emphysema, and cystic bronchiectasis. If there is no honeycombing but other criteria are met, the diagnosis is a "possible UIP pattern" radiographically as per the ATS criteria (Figure 2). Recent articles support that the possible UIP pattern likely represents an early UIP pattern. ${ }^{18,19}$

Features that would suggest an alternative diagnosis include consolidation as can be seen in organizing pneumonia (Figure 3), air trapping that is seen in hypersensitivity pneumonitis, and nodules, which are also seen in hypersensitivity pneumonitis and sarcoidosis. Ground glass opacities are frequently seen in patients with desquamative interstitial pneumonitis or respiratory bronchiolitis interstitial lung disease. Cysts occur in lymphocytic interstitial pneumonitis and lymphangioleimyomatosis among others. Bronchovascular distribution is consistent with hypersensitivity pneumonitis and NSIP and sarcoidosis. Upper lobe-predominant fibrosis is not typical of UIP and is more common with hypersensitivity pneumonitis and sarcoidosis. ${ }^{8}$

\section{Mimicker No. 1: Fibrotic NSIP \\ Clinical}

NSIP is a subtype of fibrosing IIPs and the first mimicker of UIP/IPF. In 1990s, it was reported that a subset of patients diagnosed with IPF had cellular infiltration on lung biopsy, bronchoalveolar lavage lymphocytosis, and better clinical response to anti-inflammatory therapy (ie, steroid, etc.) with a favorable long-term prognosis. ${ }^{20-23}$ NSIP histopathologic pattern is characterized by varying degree of inflammation and fibrosis with temporal uniformity (ie, varying proportions of interstitial inflammation and fibrosis seem to have occurred over a single time span, distinct from the temporal heterogeneity observed in UIP pattern). NSIP is most common among women in their 40 s to $50 \mathrm{~s}$ and nonsmokers, in contrast with UIP/IPF. NSIP

Figure 1. A "Usual interstitial pneumonitis (UIP) pattern" radiographically was defined by American Thoracic Society as subpleural basilar predominant fibrosis, reticulations, honeycombing, and absence of features that would support an alternate diagnosis.

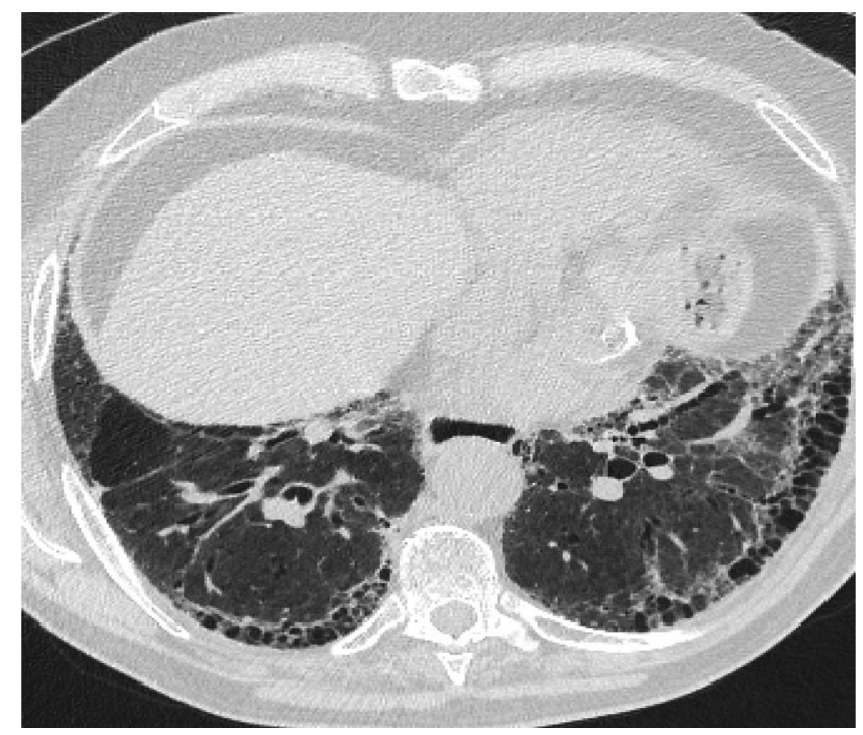


Figure 2. If there is no honeycombing but other criteria for a usual interstitial pneumonitis (UIP) pattern are met, the diagnosis is a "possible UIP pattern" radiographically as per the American Thoracic Society (ATS) criteria.

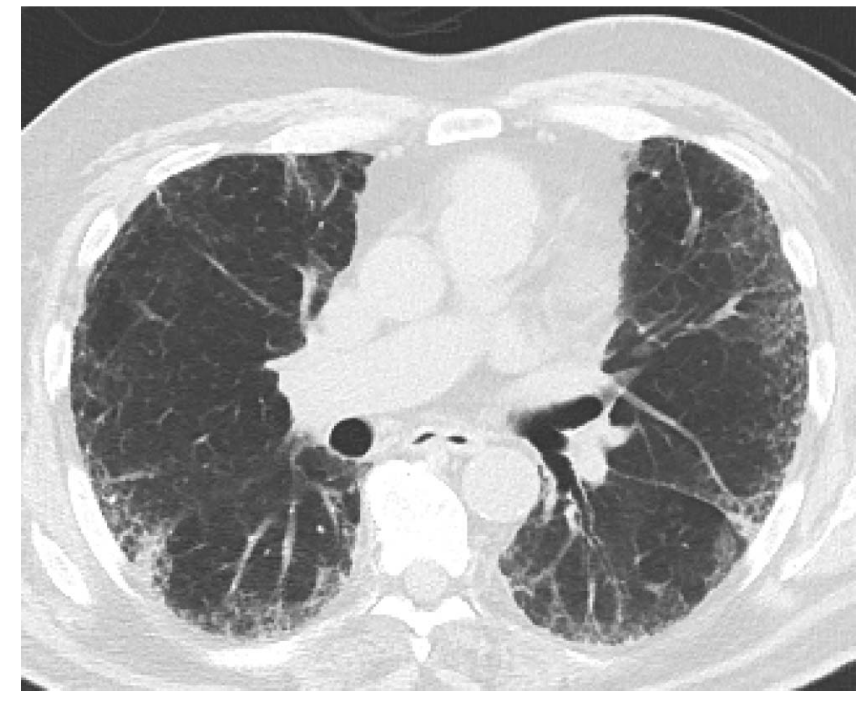

is the most common histologic finding in some forms of connective tissue disease-related ILD (CTD-ILD) which usually does not require invasive diagnostic modalities such as surgical lung biopsy for diagnosis. ${ }^{24-26}$ Therefore, specific attention should be given to connective tissue symptoms and signs (arthralgias, arthritis, skin changes, esophageal abnormalities, fever, etc.).Obtaining a comprehensive panel of serum autoantibodies and inflammatory markers, including but not limited to antinuclear antibody, rheumatoid factor,
anti-Scl-70, antisynthetase antibodies (myositis panel), anti-Ro (SS-A), anti-La (SS-B), antiribonucleoprotein, aldolase, creatine kinase, erythrocyte sedimentation rate, anticyclic citrullinated peptide, and C-reactive protein, is crucial (Table 1). Many patients present with an underlying autoimmune feature but do not meet established criteria for a CTD; therefore, ERS/ATS recently proposed the term, "interstitial pneumonia with autoimmune features" (IPAF) and offered its diagnostic criteria. ${ }^{27}$ This new guideline suggests a pos-

Figure 3. Features that would suggest an alternative diagnosis include consolidation as can be seen in organizing pneumonia, which follows the bronchovascular bundles in this example.

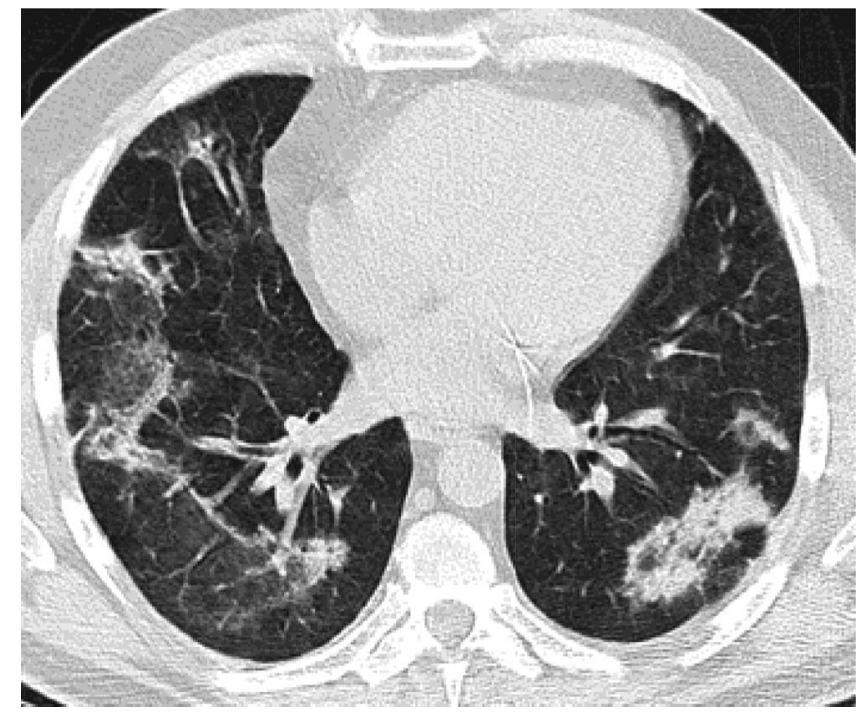


Table 1. Serologies and Their Implications in Workup of Lung Fibrosis

\begin{tabular}{ll}
\hline Lab Test & Implications When Elevated \\
\hline Anti-nuclear antibody & Collagen vascular diseases \\
Rheumatoid factor & Rheumatoid arthritis \\
Anti-Scl-70 antibody & Systemic scleroderma \\
Anti-centromere & Limited cutaneous scleroderma \\
antibody & \\
Anti-synthetase & Dermatomyositis \\
antibody & Polymyositis \\
& Anti-synthetase syndrome \\
Anti-Ro (SS-A) & Sjögren syndrome \\
antibody & Lupus erythematosus \\
Anti-La (SS-B) & Sjögren syndrome \\
antibody & Lupus erythematosus \\
Antiribonucleoprotein & Mixed connective-tissue disease \\
& LUPUS erythematosus \\
Aldolase & Dermatomyositis \\
Creatine kinase & Polymyositis \\
Erythrocyte & Dermatomyositis \\
sedimentation rate & Polymyositis \\
Anti-cyclic citrullinated & Collagen vascular diseases \\
peptide & Rheumatoid arthritis \\
\hline
\end{tabular}

sible underlying autoimmune etiology in patients with NSIP despite a lack of definitive CTD diagnosis. Moreover, since CHP and NSIP have many overlapping findings on radiography and histopathologic examination, a comprehensive environmental, occupational, and avocational history is also a critical step. After exclusion of UIP/IPF, CHP, and CTD, a clinician must confirm the histologic diagnosis obtained either by surgical lung biopsy or bronchoscopic cryobiopsy since definitive diagnosis of NSIP can only be made histologically. ${ }^{28}$ The majority of cases are typically classified as fibrosing, with less than $20 \%$ deemed to be cellular. ${ }^{29}$ As is the case with diagnosing UIP/IPF, the multidisciplinary discussion plays a key role in accurate diagnosis of NSIP and referring to ILD centers would be expected.

In mild or asymptomatic diseases, serial monitoring of symptom and pulmonary function tests are sufficient. If progression of disease is seen, treatment with immunosuppressants is thought to be beneficial. ${ }^{30,31}$ Steroids are the predominant agent of choice, whereas other immunosuppressants (azathioprine, cyclophosphamide, cyclosporine, and mycophenolate mofetil) are used to supplant steroid therapy. The prognosis for NSIP is generally favorable compared with UIP/IPF, although there is an approximate $20 \%$ mortality rate in 5 years. $^{24}$

\section{Radiology}

NSIP is a lower lobe-predominant fibrosis like UIP. However, in contrast with UIP, which is heterogeneous, NSIP is homogeneous. ${ }^{32}$ It also differs from UIP in that it is not subpleural but instead follows the bronchovascular bundles and in fact often spares the exact periphery of the lung. ${ }^{33}$ There are basically 3 types of NSIP radiographically, cellular, fibrotic, and mixed. Cellular NSIP is associated with ground glass opacities and has minimal volume loss. Cellular NSIP is more likely to respond to steroid treatment (Figure 4).

Fibrotic NSIP has less ground glass opacity and more volume loss displacing the major fissures posteriorly (Figure 5). This pattern can be confused with UIP. Fibrotic NSIP is less likely to respond to steroid treatment. In reality most cases of NSIP are mixed cellular and fibrotic with ground glass opacity and volume loss.

\section{Differentiation Pearl}

- NSIP and UIP are both lower lobe-predominant diseases; however, NSIP is distinctively different radiographically from UIP because of its homogeneity and its subpleural sparing.

- IPAF presents most common radiographically as a lower lobe-predominant fibrosis that follows the bronchovacular bundles, but unlike NSIP it is more heterogeneous.

\section{Mimicker No. 2: CHP Clinical}

CHP is an interstitial lung disease in genetically predisposed individuals caused by an exaggerated immune response to chronic inhalation of a variety of antigens in the environment (fungal, bacterial, protozoal, and animal proteins, or low-molecularweight chemical compounds, etc.). With long-term inflammation, CHP with progressive fibrosis and bronchiolitis obliterans may develop and fibrosis is often characterized by honeycombing so that in late chronic stages, histopathology may be similar to UIP or fibrotic NSIP pattern. Therefore, CHP is an important mimicker of UIP/IPF ${ }^{34-39} \mathrm{CHP}$ 
Figure 4. Cellular nonspecific interstitial pneumonitis (NSIP) is associated with ground glass opacities and has minimal volume loss. Cellular NSIP is more likely to respond to steroid treatment.

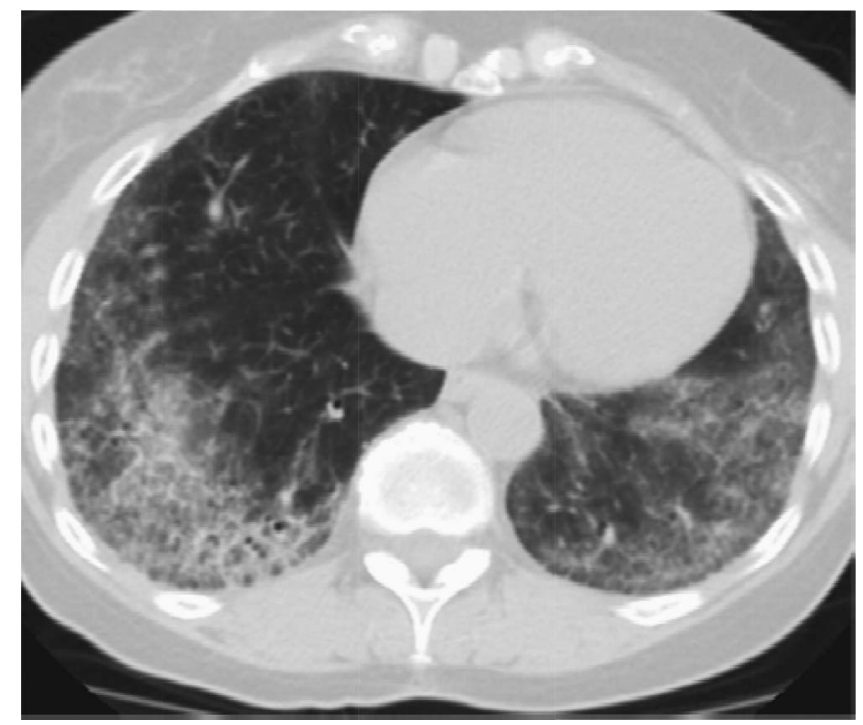

frequently occurs in the elderly female population. However, the accurate prevalence or incidence of $\mathrm{CHP}$ is difficult to evaluate given that the disease is oftentimes unrecognized or misdiagnosed and exposure conditions vary in intensity of exposure (usually low) and from place to place, and country to country. The onset of disease is insidious with gradually increasing dyspnea on exertion, dry cough, fatigue, and weight loss. Given that patients seldom relate their symptoms to the environmental exposure and the onset of respiratory symptoms is gradual, physicians often misdiagnose the disease for another interstitial lung disease such as UIP/ IPF. Diagnosis should be suspected in every patient with insidious respiratory symptoms A careful history regarding the occupational/domestic environment and hobbies is crucial (ie, bird keeping, hay feeding, feather duvet and pillows at home, air conditioning, contaminated ventilators in the buildings, and formation of mold on room walls or

Figure 5. Fibrotic nonspecific interstitial pneumonitis (NSIP) has less ground glass opacity and more volume loss then cellular NSIP. The dilated esophagus in this photograph points to the cause of fibrosis, which was scleroderma.

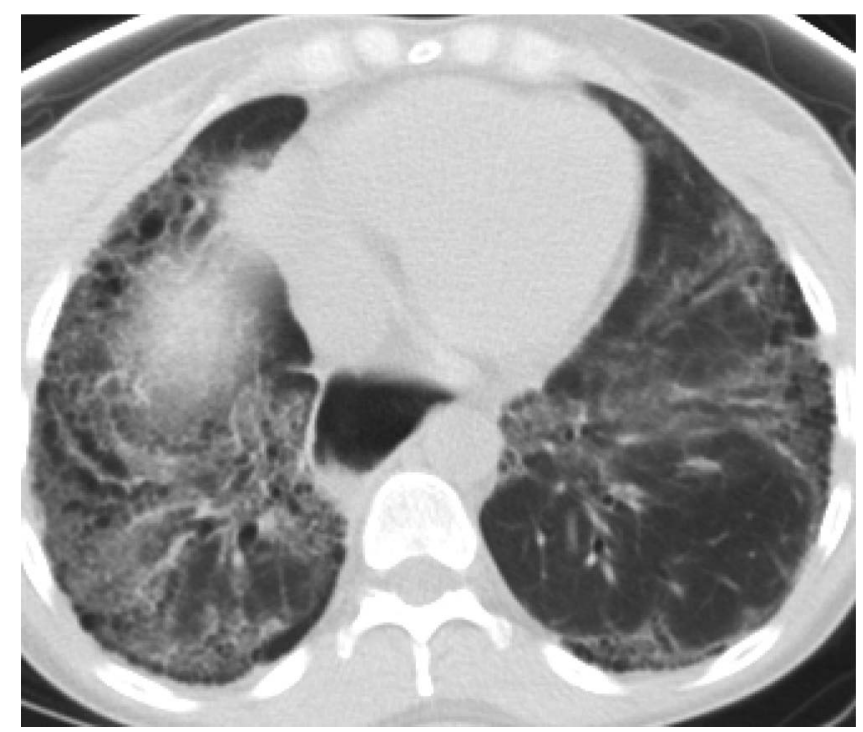


Figure 6. Chronic hypersensitivity pneumonitis (CHP) is upper-lobe predominant, airway centered, and frequently has air trapping. The most useful feature radiographically is its airway-centered distribution seen on this image.

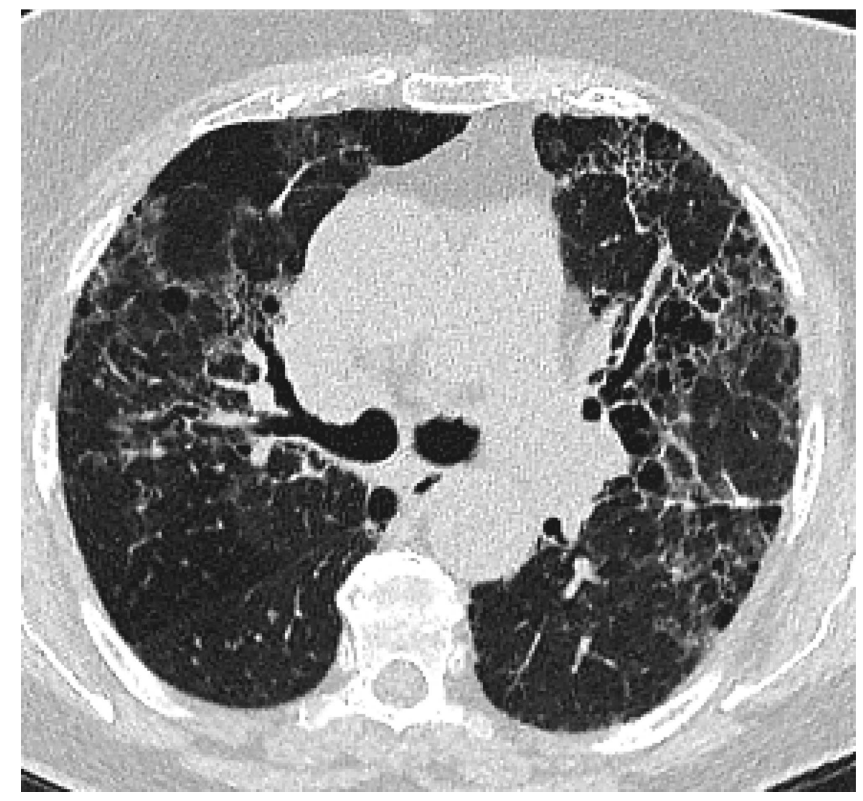

in brake fluid oils, or within wind instruments). Proof of sensitization (serum precipitins) and demonstration of a consistent pattern of this ILD on HRCT (discussed in the following "Radiology" section) support the accurate diagnosis. In contrast, pathologic diagnosis is not often required, but when obtained may demonstrate features associated with this disease even in cases with a UIP pattern (bonchocentric inflammation, lymphohystiocitic cell and poorly formed granulomas). Invasive lung biopsy may be avoided with careful history taking and radiologic evaluation by HRCT.

The prognosis of CHP varies among patients and depends on the duration of exposure to the inhaled antigen. Despite a favorable prognosis in the acute and subacute forms, CHP may become a progressive fibrotic lung disorder that results in respiratory failure even after avoiding the presumed antigen and the institution of therapy. In addition to avoidance to further antigen exposure, steroid therapy is usually recommended if patients show progressive functional impairment and immunosuppressants can be added as steroid-sparing agents. $^{35}$

\section{Radiology}

Hypersensitivity pneumonitis can be divided into acute, subacute, and chronic forms. The chronic form is most likely to mimic UIP radiographically.

Figure 7. Stage 4 sarcoidosis is an upper-lobe predominant fibrosis, which helps to differentiate it from usual interstitial pneumonitis (UIP). In addition, it is not peripheral but instead is airway centered.

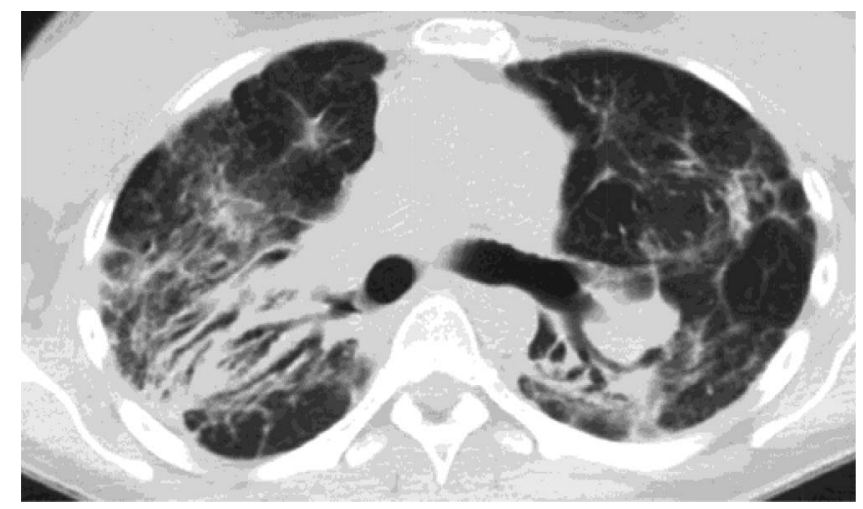


CHP is frequently misdiagnosed as IPF, which is particularly distressing because early recognition of disease and removal from antigen allows for cure. ${ }^{43}$ CHP is different from UIP radiographically mainly because instead of being peripheral, it is an airway-centered disease, which makes sense given the way in which it is acquired. Second, CHP is upper-lobe predominant and unlike UIP, which is lower-lobe predominant (Figure 6). Third, CHP frequently demonstrates air trapping on expiratory CT images. $^{41}$ Air trapping is infrequently associated with a UIP pattern and when present a diagnosis of rheumatoid arthritis should be considered. ${ }^{42}$

\section{Differentiation Pearl}

- CHP is heterogeneous like UIP but its bronchovascular distribution makes it uniquely different from UIP. Air trapping is also important in making the correct diagnosis of CHP and is rarely seen in association with UIP.

- Emphysema is frequently seen in association with UIP but rarely with CHP.

\section{Mimicker No. 3: Stage 4 Sarcoidosis Clinical}

Sarcoidosis is a multisystemic inflammatory disease of unknown etiology, characterized by the presence of noncaseating granulomas, and predominantly affecting lung. In the majority of patients, pulmonary sarcoidosis undergoes clinical remission either spontaneously or with therapy and favorable long-term outcomes are achieved. However, approximately $20 \%$ of patients develop pulmonary fibrosis (ie, radiographic stage iv sarcoidosis) with substantially increased mortality, therefore it can be another mimicker of UIP/IPF. ${ }^{43,44}$ Stage 4 Sarcoidosis is a fibroticdisease with little or no granulomatous inflammation and clinical improvement is not expected with anti-inflammatory therapy. ${ }^{45}$ Fibrosis in sarcoidosis originates from granuloma and along with bronchovascular bundles may result in bronchial distortion and large cystic changes, and interlobular septal fibrosis results in linear scarring. ${ }^{46}$ The histologic features of UIP pattern (honeycombing, fibroblast foci, etc) are not typical in sarcoidosis. In sarcoidosis, wheezing, which is attributed to airway-centric fibrosis is common, although patients are less symptomatic than UIP/IPF. ${ }^{47,48}$ In contrast with IPF, acute ex-

Table 2. Overview of Common Fibrotic Lung Diseases

\begin{tabular}{|c|c|c|c|}
\hline & Pulmonary & Radiology & Treatment \\
\hline \multirow[t]{3}{*}{ UIP } & Older age & Subpleural & Anti fibrotic medications \\
\hline & Male sex & Basilar predominant & $\begin{array}{l}\text { Consider referral for lung transplant } \\
\text { soon after diagnosis as course is } \\
\text { unpredictable and inexorable }\end{array}$ \\
\hline & $\begin{array}{l}\text { Smoking history } \\
\text { Crackles at lung bases } \\
\text { Clubbing }\end{array}$ & Honeycombing & $\begin{array}{l}\text { Anti-inflammatory and } \\
\text { immunosuppressive Rx NOT } \\
\text { indicated (may be harmful) }\end{array}$ \\
\hline \multirow[t]{5}{*}{ NSIP } & Younger age & Homogeneous & Anti-inflammatory medications \\
\hline & Female sex & Bronchovascular & Consider referral for lung transplant \\
\hline & Connective tissue disease & Lower lobe & if advanced disease \\
\hline & Positive serologies & Dilated esophagus & \\
\hline & & Peripheral sparring & \\
\hline \multirow[t]{4}{*}{$\mathrm{CHP}$} & Older age & Peribronchiolar fibrosis & Anti-inflammatory medications \\
\hline & Female & Air trapping & Removal of causative antigen \\
\hline & Bird owner & Upper lobe & Consider referral for lung transplant \\
\hline & Mold exposure & & di dicoco \\
\hline \multirow[t]{3}{*}{ S4 } & Younger age & Upper lobe posterior & Anti-inflammatory medications \\
\hline & Less symptomatic & Calcified lymph nodes & Consider transplantation for \\
\hline & & Peribronchiolar fibrosis & $\begin{array}{l}\text { advanced disease (PHN, } \\
\text { hypoxemia, declining PFT's) }\end{array}$ \\
\hline
\end{tabular}

CHP, chronic hypersensitivity pneumonitis; NSIP, non-specific interstitial pneumonitis; S4, stage 4 sarcoidosis; PFT, Pulmonary Function Test; PHN, pulmonary hypertension; UIP, usual interstitial pneumonitis. 
acerbations of disease attributed to diffuse alveolar damage have not been reported in stage 4 sarcoidosis. $^{43}$

Treatment is indicated in patients who are symptomatic, with progressively worsening pulmonary function. ${ }^{44}$ Pulmonary fibrosis is an irreversible event, but in at least some patients, fibrosis coexists with active granulomatous inflammation. This is often difficult to discern and tests that suggest activity such as Gallium or Positron Emission Tomography (PET) scan are utilized to guide therapy. Treatments include multiple modalities aimed at suppressing inflammation with the use of anti-inflammatory agents (corticosteroids, methotrexate, azathioprine, leflunomide, mycophenolate mofetil, TNF antagonist, etc.). Although life expectancy is longer in S4 compared with UIP/IPF, once patients develop end-stage fibrotic lung disease, survival is limited and lung transplantation may be the treatment of last resort as it is for selected patients with pulmonary UIP/IPF. ${ }^{43}$

\section{Radiology}

Stage 1 sarcoidosis demonstrates hilar and mediastinal lymphadenopathy, stage 2 sarcoidosis manifests as adenopathy and pulmonary nodules or den-

Table 3. Putting It All Together: Typical Scenarios for Patients with Lung Fibrosis

\begin{tabular}{|c|c|c|c|c|}
\hline & IPF & NSIP & CHP & S4 \\
\hline Clinical presentation & $\begin{array}{l}\text { 74-year-old male } \\
\text { with history of } \\
\text { smoking, } \\
\text { cough, and } \\
\text { progressive } \\
\text { DOE }\end{array}$ & $\begin{array}{l}\text { 45-year-old female } \\
\text { with history of } \\
\text { connective } \\
\text { tissue disease } \\
\text { and shortness of } \\
\text { breath }\end{array}$ & $\begin{array}{l}\text { 68-year-old female. } \\
\text { male with shortness } \\
\text { of breath and } \\
\text { parakeet/parrot } \\
\text { (hobbies/occupations) } \\
\text { Absent history of } \\
\text { smoking }\end{array}$ & $\begin{array}{l}\text { 30-year-old male with } \\
\text { cough, DOE }\end{array}$ \\
\hline Exams & $\begin{array}{l}\text { Crackles at lung } \\
\text { bases on } \\
\text { physical exam }\end{array}$ & $\begin{array}{l}\text { Evidence of rash } \\
\text { on extensor } \\
\text { surfaces. }\end{array}$ & $\begin{array}{l}\text { Squeaks and airway } \\
\text { sounds as well as } \\
\text { rales testing for } \\
\text { sensitivity to antigens } \\
\text { causing fibrosis }\end{array}$ & $\begin{array}{l}\text { Restrictive, obstructive } \\
\text { or mixed pulmonary } \\
\text { function tests }\end{array}$ \\
\hline & $\begin{array}{l}\text { Digital clubbing } \\
\text { Restrictive } \\
\text { pulmonary } \\
\text { function tests } \\
\text { with decreased } \\
\text { DLCO }\end{array}$ & $\begin{array}{l}\text { Capillary testing } \\
\text { of fingers } \\
\text { Restrictive } \\
\text { pulmonary } \\
\text { function tests } \\
\text { with decreased } \\
\text { DLCO }\end{array}$ & $\begin{array}{l}\text { Restrictive pulmonary } \\
\text { function tests with } \\
\text { decreased DLCO }\end{array}$ & $\begin{array}{l}\text { Hx of sarcoidosis or } \\
\text { evidence of } \\
\text { granulomatous } \\
\text { inflammation and } \\
\text { multisystemic } \\
\text { involvement }\end{array}$ \\
\hline Radiology & $\begin{array}{l}\text { Subpleural basilar } \\
\text { predominant } \\
\text { fibrosis with } \\
\text { honeycombing } \\
\text { compatible with } \\
\text { ATS criteria for } \\
\text { a UIP pattern }\end{array}$ & $\begin{array}{l}\text { Lower lobe } \\
\text { fibrosis which } \\
\text { follows the } \\
\text { bronchovascular } \\
\text { bundles and is } \\
\text { homogeneous. } \\
\text { Sometimes } \\
\text { there is } \\
\text { peripheral } \\
\text { sparring }\end{array}$ & $\begin{array}{l}\text { Heterogeneous fibrosis } \\
\text { that follows the } \\
\text { bronchovascular } \\
\text { bundles with slight } \\
\text { upper lobe } \\
\text { predominance } \\
\text { There is usually air } \\
\text { trapping }\end{array}$ & $\begin{array}{l}\text { Upper lobe posterior } \\
\text { fibrosis sometimes } \\
\text { with calcified } \\
\text { mediastinal lymph } \\
\text { nodes }\end{array}$ \\
\hline Treatment & $\begin{array}{l}\text { Anti-fibrotic } \\
\text { medication } \\
\text { Pulmonary } \\
\text { rehabilitation } \\
\text { Treat esophageal } \\
\text { reflux disease }\end{array}$ & $\begin{array}{l}\text { Anti-inflammatory } \\
\text { medications } \\
\text { Rheumatology } \\
\text { consult }\end{array}$ & $\begin{array}{l}\text { Anti-inflammatory } \\
\text { medications } \\
\text { Removal of antigen } \\
\text { causing disease if } \\
\text { known }\end{array}$ & $\begin{array}{l}\text { Anti-inflammatory } \\
\text { medications }\end{array}$ \\
\hline Role of transplant & $\begin{array}{l}\text { Referral for } \\
\text { transplant } \\
\text { evaluation early } \\
\text { after diagnosis } \\
\text { or for } \\
\text { progressive } \\
\text { disease }\end{array}$ & $\begin{array}{l}\text { Referral for } \\
\text { transplant } \\
\text { evaluation for } \\
\text { advanced disease }\end{array}$ & $\begin{array}{l}\text { Referral for transplant } \\
\text { evaluation for } \\
\text { advanced disease }\end{array}$ & $\begin{array}{l}\text { Referral for transplant } \\
\text { evaluation for } \\
\text { advanced disease }\end{array}$ \\
\hline
\end{tabular}

CHP, chronic hypersensitivity pneumonitis; DLCO, Diffusion Capacity of Lungs for Carbon Monoxide; DOE, dyspnea on exertion; IPF, idiopathic pulmonary fibrosis; NSIP, nonspecific interstitial pneumonitis; S4, stage 4 sarcoidosis. 
sities in a peri-lymphatic distribution, stage 3 sarcoidosis has parenchymal involvement without lymphadenopathy, and stage 4 disease presents with fibrosis of the lung, which needs to be differentiated from UIP and CHP (Figure 7). Stage 4 sarcoid is an upper lobe-predominant fibrosis, which helps to differentiate it from UIP. In addition, it is not peripheral but instead is airway centered. Unlike CHP it tends to be posterior in the upper lobe and there is no air trapping. ${ }^{49,50}$

\section{Differentiation Pearl}

- Sarcoidosis has more in common radiographically with NSIP and CHP than with UIP because the fibrosis is not peripheral but instead follows the bronchovascular bundles.

- Its upper-lobe predominance helps to differentiate S4 from NSIP.

- A posterior predominance and absence of air trapping helps to differentiate S4 from CHP, which is upper lobe but more frequently anterior.

\section{Conclusion}

UIP/IPF has a poor prognosis with a mean life expectancy of 3.8 years. The American Thoracic Society (ATS) has provided guidelines for the accurate diagnosis of IPF. This is a diagnosis of exclusion. There must be no known cause for a patient's lung fibrosis. The CT scan must show a UIP pattern with subpleural basilar-predominant fibrosis and honeycombing and absence of features that would suggest alternative diagnoses. A "possible UIP pattern" by ATS criteria includes the same criteria except honeycombing. If the patient does not have $\mathrm{HC}$ a lung biopsy may be considered to make the definitive diagnosis. ${ }^{8}$

In 2014, 2 antifibrotic medications, nintedanib and pirfenidone, were approved in the United States for the treatment of IPF. These daily administered medications are expensive but are often covered by insurance if patient has a diagnosis of UIP/ IPF. These target multiple pathways of UIP $^{51}$ and slow the decline of the forced vital capacity (FVC). They may be helpful in other fibrotic lung disease but his has not been studied. Therefore, it is now critical to diagnose IPF early and accurately. Early referral to a pulmonologist with expertise in lung fibrosis may be beneficial. The early and correct diagnosis is challenged by mimickers which have similarities to UIP/IPF and include NSIP, CHP, and sarcoidosis. Fortunately, careful clinical history, serologic testing, CT inspection, and multidisciplinary discussion can establish the correct diagnosis without an invasive procedure (Tables 2 and 3). It has been the goal of this article to share with primary care clinicians the most important aspects of the clinical and radiology presentation of IPF and its mimickers so that you will be able to correctly and noninvasively diagnosis UIP/IPF.

To see this article online, please go to: http://jabfm.org/content/ 31/1/151.full.

\section{References}

1. Ramazzini B. Diseases of workers (Wright WC, trans). New York, NY: Hafner; 1964, 243.

2. Knoll MA, Salvatore M, Sheu RD, et al. The use of isodose levels to interpret radiation induced lung injury: A quantitative analysis of computed tomography changes. Quant Imaging Med Surg 2016;6:35-41.

3. Salvatore M, Henschke CI, Yip R, et al. Osteophyte induced lung fibrosis prevalence and osteophyte qualities predicting disease. Clin Imag 2017;44:1-4.

4. Liebow AA, Carrington CB. The interstitial pneumonias. In: Simon M, Potchen EJ, LeMay M, eds. Frontiers of pulmonary radiology. 1st ed. New York, NY: Grune \& Stratton; 1969, 102-141.

5. Travis WD, Costabel U, Hansell DM, et al. An official American Thoracic Society/European Respiratory Society statement: Update of the international multidisciplinary classification of the idiopathic interstitial pneumonias. Am J Respir Crit Care Med 2013;188:733-48.

6. Nathan SD, Shlobin OA, Weir N, et al. Longterm course and prognosis of idiopathic pulmonary fibrosis in the new millennium. Chest 2011; 140:221-9.

7. Raghu G, Chen SY, Yeh WS, et al. Idiopathic pulmonary fibrosis in US Medicare beneficiaries aged 65 years and older: Incidence, prevalence, and survival, 2001-11. Lancet Respir Med 2014;2:566-72.

8. Raghu G, Collard HR, Egan JJ, et al. An official ATS/ERS/JRS/ALAT statement: Idiopathic pulmonary fibrosis: Evidence-based guidelines for diagnosis and management. Am J Respir Crit Care Med 2011;183:788-824.

9. King TE Jr, Pardo A, Selman M. Idiopathic pulmonary fibrosis. Lancet 2011;378:1949-61.

10. Jo HE, Corte TJ, Moodley Y, et al. Evaluating the interstitial lung disease multidisciplinary meeting: A survey of expert centres. BMC Pulm Med 2016;16:22.

11. Raghu G, Anstrom KJ, King TE Jr, Lasky JA, Martinez FJ . Prednisone, azathioprine, and N-acetylcys- 
teine for pulmonary fibrosis. N Engl J Med 2012; 366:1968-77.

12. Raghu G, Brown KK, Bradford WZ, et al. A placebo-controlled trial of interferon gamma-1b in patients with idiopathic pulmonary fibrosis. N Engl J Med 2004;350:125-33.

13. Noble PW, Albera C, Bradford WZ, et al. Pirfenidone in patients with idiopathic pulmonary fibrosis (CAPACITY): Two randomised trials. Lancet 2011; 377:1760-9.

14. Richeldi L, Costabel U, Selman M, et al. Efficacy of a tyrosine kinase inhibitor in idiopathic pulmonary fibrosis. N Engl J Med 2011;365:1079-87.

15. Richeldi L, du Bois RM, Raghu G, et al. Efficacy and safety of nintedanib in idiopathic pulmonary fibrosis. N Engl J Med 2014;370:2071-82.

16. Webb WR, Muller NL, Naidich DP. High resolution CT of the lung. 4th ed. Philadelphia, PA: Lippincott Williams and Wilkins, 2009.

17. Arakawa H, Honma K. Honeycomb lung: History and current concepts. AJR 2011;196:773-82.

18. Yamauchi H, Bando M, Baba T, et al. Clinical Course and Changes in High-Resolution Computed Tomography Findings in Patients with Idiopathic Pulmonary Fibrosis without Honeycombing. PLoS One 2016;11:e0166168.

19. Raghu G, Wells AU, Nicholson AG, et al. Effect of nintedanib in subgroups of idiopathic pulmonary fibrosis by diagnostic criteria. Am J Respir Crit Care Med 2017;195:78-85.

20. Bjoraker JA, Ryu JH, Edwin MK, et al. Prognostic significance of histopathologic subsets in idiopathic pulmonary fibrosis. Am J Respir Crit Care Med 1998;157:199-203.

21. Nicholson AG, Colby TV, du Bois RM, Hansell DM, Wells AU. The prognostic significance of the histologic pattern of interstitial pneumonia in patients presenting with the clinical entity of cryptogenic fibrosing alveolitis. Am J Respir Crit Care Med 2000;162:2213-7.

22. Daniil ZD, Gilchrist FC, Nicholson AG, et al. A histologic pattern of nonspecific interstitial pneumonia is associated with a better prognosis than usual interstitial pneumonia in patients with cryptogenic fibrosing alveolitis. Am J Respir Crit Care Med 1999;160:899-905.

23. Nagai S, Kitaichi M, Itoh H, Nishimura K, Izumi T, Colby TV. Idiopathic nonspecific interstitial pneumonia/fibrosis: Comparison with idiopathic pulmonary fibrosis and BOOP. Eur Respir J 1998;12:1010-9.

24. Arakawa H, Yamada H, Kurihara Y, et al. Nonspecific interstitial pneumonia associated with polymyositis and dermatomyositis: serial high-resolution CT findings and functional correlation. Chest 2003; 123:1096-103.

25. Kim DS, Yoo B, Lee JS, et al. The major histopathologic pattern of pulmonary fibrosis in scleroderma is nonspecific interstitial pneumonia. Sarcoidosis Vasc Diffuse Lung Dis 2002;9:121-7.

26. Yamadori I, Fujita J, Bandoh S, et al. Nonspecific interstitial pneumonia as pulmonary involvement of primary Sjögren's syndrome. Rheumatol Int 2002; 22:89-92.

27. Fischer A, Antoniou KM, Brown KK, et al. An official European Respiratory Society/American Thoracic Society research statement: Interstitial pneumonia with autoimmune features. Eur Respir J 2015; 46:976-87.

28. Belloli EA, Beckford R, Hadley R, Flaherty KR. Idiopathic non-specific interstitial pneumonia. Respirology 2016;21:259-68.

29. Travis WD, Hunninghake G, King TE Jr, et al. Idiopathic nonspecific interstitial pneumonia: Report of an American Thoracic Society project. Am J Respir Crit Care Med 2008;177:1338-47.

30. Park IN, Jegal Y, Kim DS, et al. Clinical course and lung function change of idiopathic nonspecific interstitial pneumonia. Eur Respir J 2009;33:68-76.

31. Lee JY, Jin SM, Lee BJ, Chung DH, et al. Treatment response and long term follow-up results of nonspecific interstitial pneumonia. J Korean Med Sci 2012;27:661-7.

32. Smith ML. Update on pulmonary fibrosis: Not all fibrosis is created equally. Arch Pathol Lab Med 2016;140:221-9.

33. Johkoh T. Nonspecific interstitial pneumonia and usual interstitial pneumonia: Is differentiation possible by high-resolution computed tomography? Semin Ultrasound CT MR 2014;35:24-8.

34. Trahan S, Hanak V, Ryu JH, Myers JL. Role of surgical lung biopsy in separating chronic hypersensitivity pneumonia from usual interstitial pneumonia/idiopathic pulmonary fibrosis: Analysis of $31 \mathrm{bi}-$ opsies from 15 patients. Chest 2008;134:126-32.

35. Ohtani Y, Saiki S, Kitaichi M, et al. Chronic bird fancier's lung: histopathological and clinical correlation. An application of the 2002 ATS/ERS consensus classification of the idiopathic interstitial pneumonias. Thorax 2005;60:665-71.

36. Churg A, Sin DD, Everett D, Brown K, Cool C. Pathologic patterns and survival in chronic hypersensitivity pneumonitis. Am J Surg Pathol 2009;33: 1765-70.

37. Lima MS, Coletta EN, Ferreira RG, et al. Subacute and chronic hypersensitivity pneumonitis: Histopathological patterns and survival. Respir Med 2009; 103:508-15.

38. Gaxiola M, Buendía-Roldán I, Mejía M, et al. Morphologic diversity of chronic pigeon breeder's disease: Clinical features and survival. Respir Med 2011;105:608-14.

39. Vourlekis JS, Schwarz MI, Cool CD, et al. Nonspecific interstitial pneumonitis as the sole histologic expression of hypersensitivity pneumonitis. Am J Med 2002;112:490-3. 
40. Salisbury ML, Myers JL, Belloli EA, Kazerooni EA, Martinez FJ, Flaherty KR. Diagnosis and treatment of fibrotic hypersensitivity pneumonia. Where we stand and where we need to go. Am J Respir Crit Care Med. 2017;196:690-9.

41. Torres PP, Moreira MA, Silva DG, da Gama RR, Sugita DM, Moreira MA. High-resolution computed tomography and histopathological findings in hypersensitivity pneumonitis: A pictorial essay. Radiol Bras 2016;49:112-6.

42. Park WH, Kim SS, Shim SC, et al. Visual Assessment of chest computed tomography findings in anti-cyclic citrullinated peptide antibody positive rheumatoid arthritis: Is it associated with airway abnormalities? Lung 2016;194:97-105.

43. Rybicki BA, Major M, Popovich J Jr, et al. Racial differences in sarcoidosis incidence: A 5-year study in a health maintenance organization. Am J Epidemiol 1997; 145:234-241.

44. Baughman RP, Teirstein AS, Judson MA, et al. Clinical characteristics of patients in a case control study of sarcoidosis. Am J Respir Crit Care Med 2001; 164(10 Pt 1):1885-9.
45. Patterson KC, Strek ME. Pulmonary fibrosis in sarcoidosis. Clinical features and outcomes. Ann Am Thorac Soc 2013;10:362-70.

46. Ramachandraiah V, Aronow W, Chandy D. Pulmonary sarcoidosis: An update. Postgrad Med 2017;129: 149-158.

47. Nunes H, Humbert M, Capron F, et al. Pulmonary hypertension associated with sarcoidosis: Mechanisms, haemodynamics and prognosis. Thorax 2006;61: 68-74.

48. Teirstein AT, Morgenthau AS. "End-stage" pulmonary fibrosis in sarcoidosis. Mt Sinai J Med 2009;76: $30-6$.

49. Hansell DM, Milne DG, Wilsher ML, Wells AU. Pulmonary sarcoidosis: morphologic associations of airflow obstruction at thin-section CT. Radiology 1998;209:697-704.

50. Criado E, Sánchez M, Ramírez J, et al. Pulmonary sarcoidosis: typical and atypical manifestations at high-resolution CT with pathologic correlation. Radiographics 2010;30:1567-86.

51. Pollack A. F.D.A. approves first 2 drugs for treatment of a fatal lung disease. NY Times. October 14, 2014. 